\title{
Environmental Risk Factors for Congenital Heart Disease
}

\author{
Jacinta Isabelle Kalisch-Smith, ${ }^{1}$ Nikita Ved, ${ }^{1}$ and Duncan Burnaby Sparrow \\ Department of Physiology, Anatomy and Genetics, University of Oxford, Oxford, Oxfordshire OX1 3PT, \\ United Kingdom \\ Correspondence: duncan.sparrow@dpag.ox.ac.uk
}

\begin{abstract}
Congenital heart disease (CHD) has many forms and a wide range of causes. Clinically, it is important to understand the causes. This allows estimation of recurrence rate, guides treatment options, and may also be used to formulate public health advice to reduce the population prevalence of $\mathrm{CHD}$. The recent advent of sophisticated genetic and genomic methods has led to the identification of more than 100 genes associated with CHD. However, despite these great strides, to date only one-third of CHD cases have been shown to have a simple genetic cause. This is because CHD can also be caused by oligogenic factors, environmental factors, and/or gene-environment interaction. Although solid evidence for environmental causes of CHD have been available for almost 80 years, it is only very recently that the molecular mechanisms for these risk factors have begun to be investigated. In this review, we describe the most important environmental CHD risk factors, and what is known about how they cause CHD.
\end{abstract}

Thersing he reasons for the frequent occurrence of birth defects has invited speculation since ancient times. Although the ancient Greeks recognized that some birth defects might be inherited, they also speculated that they might occur by bad influences during pregnancy. In the following millennia, the latter hypothesis was predominant, right up until the rediscovery of Mendel's work on genetics in the early twentieth century. For example, the early cardiac anatomist Thomas Peacock wrote in 1858: "The occurrence of accidents and strong impressions upon the mind of the mother are also supposed to conduce to the irregular development of the offspring" (Peacock 1858). He also noted that other cases appeared to have "an hereditary predisposition to defective development of the heart." Fifty years later, the pioneering cardiac pathologist Maud Abbott wrote that congenital heart disease (CHD) could occur through "baneful influences acting on the mother during the early weeks of pregnancy" (Abbott 1908). She also conceded that heredity might play some role, although not as strongly as in other birth defects such as polydactyly. The environmental hypothesis received its first solid evidence with the discovery in 1941 that maternal rubella infection could cause a suite of birth defects, including CHD (Gregg 1941). Despite this, by the late 1940s, the mood was shifting in favor

\footnotetext{
${ }^{1}$ These authors contributed equally to this work. Editors: Benoit G. Bruneau and Paul R. Riley

Additional Perspectives on Heart Development and Disease available at www.cshperspectives.org

Copyright $\odot 2020$ Cold Spring Harbor Laboratory Press; all rights reserved; doi: 10.1101/cshperspect.a037234 Cite this article as Cold Spring Harb Perspect Biol 2020;12:a037234
} 
of genetics as the major cause of CHD (Taussig 1947; Campbell 1949) and by 1959 there was the first clear evidence for this with the identification of the chromosomal abnormalities underlying Down syndrome (Lejeune et al. 1959) and Turner syndrome (Ford et al. 1959). Despite the identification 2 years later of exposure to the morning sickness drug thalidomide as another environmental cause of CHD (Lenz 1961; McBride 1961; Pfeiffer and Kosenow 1961), by the 1960s the majority view was that genetics was the most important cause of CHD, and environmental factors were relegated to probably only having a supporting role in gene-environment interactions (Nora 1968). From the 1970s onward, chromosomal deletions and genetic mapping studies identified approximate genome locations for a dozen or so inherited forms of CHD. This process accelerated with the advent of molecular biology in the 1980s, and by 1991 the first gene mutation associated with CHD was identified: FIBRILLIN in Marfan syndrome (Dietz et al. 1991). The rapid advances in genetic diagnoses captured the imagination of scientists and the general public alike, and research into possible environmental causes of CHD became unfashionable. In the 20 years since the sequencing of the human genome, intensive effort has been focused on understanding the genetic causes of CHD. This has been coupled with great advances in uncovering the morphological and molecular processes driving embryonic heart development (Rickert-Sperling et al. 2016). However, despite these efforts and the discovery of almost 100 genes associated with human $\mathrm{CHD}$, routine whole-genome sequencing of large numbers of $\mathrm{CHD}$ patients and their families has only provided genetic explanations for $\sim 30 \%$ of CHD cases (Szot et al. 2018). Thus, scientific interest has returned to nongenetic cases and uncovering the environmental causes of CHD. In this review, we will discuss the best-known environmental risk factors for CHD and what is known about how they perturb embryonic heart development. We have divided these into two broad categories: extrinsic factors, such as teratogen exposure and nutrient deficiencies, and intrinsic factors, including maternal disease and illness.

\section{TYPES OF CONGENITAL HEART DISEASE}

$\mathrm{CHD}$ is a general term for a structural or functional defect of the heart that is present at birth. The heart is a complex organ formed from cells derived from at least four distinct progenitor cell types, termed the "first heart field (FHF)," "second heart field (SHF)," "cardiac neural crest," and the "proepicardial organ" (for a review, see Rickert-Sperling et al. 2016). Perturbation of any stage of this process can cause a variety of effects, depending on the timing and nature of the perturbing factor. As a result, there are more than 20 specific types of CHD. These range in severity from mild defects, which may have very little effect on the patient, through to critical $\mathrm{CHD}$, which will require immediate surgery and carries a high rate of morbidity and mortality. Here we summarize the most important forms of CHD that may be induced by exposure to environmental factors. In general, CHD can be divided into several broad classes, based on their embryological origins. Conotruncal defects result from an abnormal formation of the outflow tract (OFT) of the heart. These include (1) ventricular septal defects (VSDs), where a hole is present between the ventricles (Fig. 1B); (2) double outlet right ventricle (DORV), which is a defective alignment of the aorta and pulmonary trunk, such that both vessels drain the right ventricle. This is also commonly associated with a VSD (Fig. 1C); (3) overriding aorta (OA), a defective alignment of the aorta directly over a VSD (Fig. 1D); (4) transposition of the great arteries (TGAs), where the aorta connects to the right ventricle and the pulmonary trunk to the left ventricle (Fig. 1E); and (5) persistent truncus arteriosus (PTA), also called common arterial trunk (CAT), where the septum dividing the aorta and pulmonary trunk fully or partially fails to form (Fig. 1F). Also, in this group, tetralogy of Fallot (TOF) is a commonly observed association of four heart defects: VSD, pulmonary artery stenosis, OA, and right ventricular hypertrophy (Fig. 1G). Venous pole defects occur where the inflow tract fails to form correctly. These include (1) atrial septal defect (ASD), where a hole is present between the atria; and (2) atrioventricular septal defect (AVSD), 
A

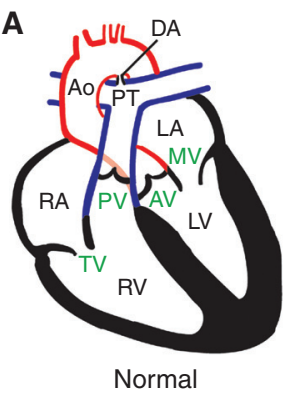

E

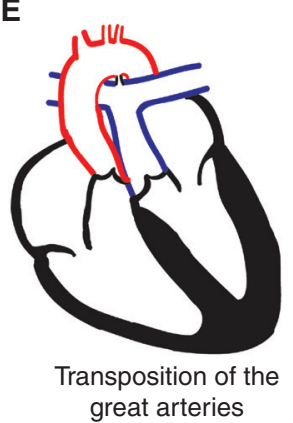

I

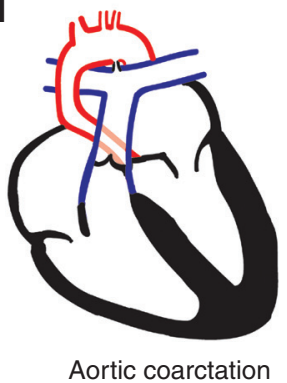

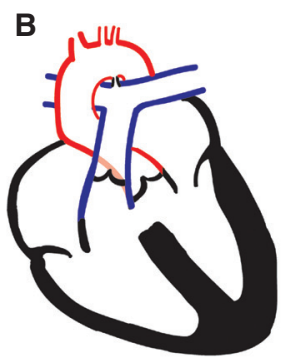

Ventricular septal defect

$\mathbf{F}$

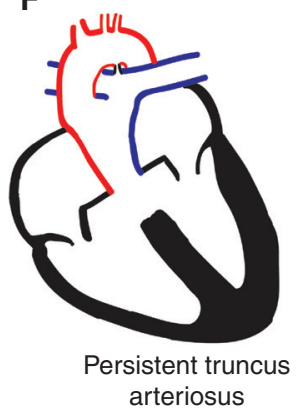

RV: Right ventricle

RA: Right atrium

LA: Left atrium

LV: Left ventricle

TV: Tricuspid valve

MV: Mitral valve

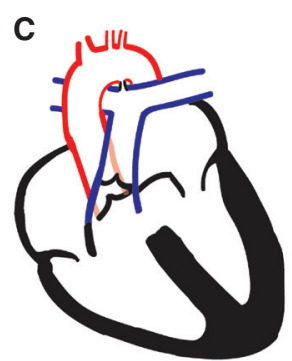

Double outlet right ventricle

G

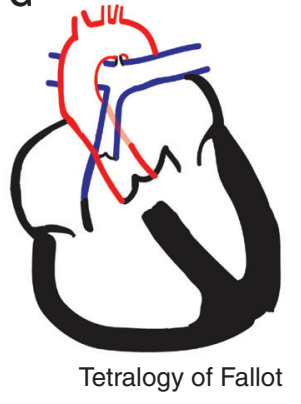

PV: Pulmonary valve PT: Pulmonary trunk AV: Aortic valve

Ao: Aorta

DA: Ductus arteriosus

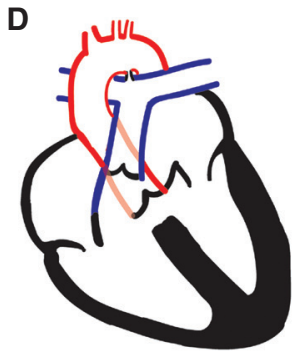

Overriding aorta

H

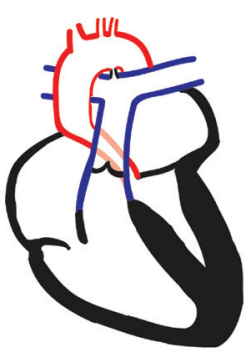

Hypoplastic left heart syndrome

Figure 1. Schematic diagrams $(A-I)$ showing the structures of some of the most important forms of congenital heart disease $(\mathrm{CHD})$ induced by exposure to environmental factors.

complete failure of the atrioventricular (AV) septum, resulting in a hole that allows communication between all four cardiac chambers. Left ventricular obstructive lesions occur when the aorta fails to form correctly. These include (1) hypoplastic left heart syndrome (HLHS), where there is no outlet to the left ventricle (Fig. 1H); (2) aortic coarctation and/or stenosis, where the lumen of the aorta is abnormally thin (Fig. 1I); and (3) bicuspid aortic valve (BAV), where the aortic valve fails to form the normal three leaflets. Another important valve defect is Ebstein's anomaly, a malformation of the tricuspid valve between the right atrium and right ventricle. Finally, CHD can present with abnormalities of the smaller vessels leaving the heart, in particular: (1) aortic arch anomalies (AAAs) or interrupted aortic arch (IAA) are where there is a discontinuity between the ascending and descending aortae. There are three types of IAA: type A occurs distal to the left subclavian artery; type B occurs between the left carotid artery and the left subclavian artery; and type $\mathrm{C}$ occurs between the right and left carotid artery; (2) persistent ductus arteriosus (PDA), a connection between the aorta and pulmonary artery that is open in the fetus, but normally closes a few days after birth; and (3) branch pul- 
J.I. Kalisch-Smith et al.

monary artery stenosis, where the branching arteries entering the lungs are narrow or blocked. For reference, the estimated birth prevalence of these forms of CHD (taken from Bruneau 2008) are given in Table 1.

\section{EXTRINSIC FACTORS}

Normal embryonic development is a carefully choreographed and robust process that is nonetheless vulnerable to perturbation by external factors. Such factors can be either an excess of a toxic substance, or the lack of an essential nutrient. In both cases, the factor can act directly on the embryo itself or indirectly, for example, by perturbing placental development and altering the nutrient supply to the embryo.

\section{Teratogens \\ Thalidomide}

The most notorious human teratogen is thalidomide. This was introduced in the 1950s to treat influenza, then used as a sedative, and finally as an antiemetic for morning sickness in pregnan-

Table 1. Estimated prevalence of various forms of congenital heart disease (CHD)

\begin{tabular}{lc}
\hline CHD type & $\begin{array}{r}\text { Estimated prevalence } \\
\text { per 1000 births }\end{array}$ \\
\hline Ventricular septal defect & 4.0 \\
Double outlet right ventricle & 0.2 \\
Overriding aorta & na \\
Transposition of the great & 0.2 \\
$\quad$ arteries & 0.1 \\
Persistent truncus arteriosus & 0.4 \\
Tetralogy of Fallot & 1.0 \\
Atrial septal defect & 0.3 \\
Atrioventricular septal defect & 0.2 \\
Hypoplastic left heart & \\
$\quad$ syndrome & 0.8 \\
Aortic coarctation/stenosis & 14.0 \\
Bicuspid aortic valve & 0.8 \\
Persistent ductus arteriosus & na \\
Branch pulmonary artery & \\
$\quad$ stenosis &
\end{tabular}

${ }^{\mathrm{a}}$ Information based on data in Bruneau (2008). cy. It was withdrawn in the early 1960s, following widespread reports of its association with severe limb defects (Lenz 1961). It is less well known that thalidomide also caused CHD in $\sim 30 \%$ of cases (Ruffing 1977). In recent years, thalidomide usage in the clinic has resumed for treatment of Hansen's disease (leprosy) and relapsed-refractory multiple myeloma, albeit with tight contraceptive control in young women. The experience with thalidomide emphasizes one potential problem with the use of animal models to test the teratogenicity of drugs. Orally administered thalidomide is not teratogenic in rats, but it is highly teratogenic in both humans and rabbits (Schumacher et al. 1968). To further complicate matters, thalidomide forms two optical isomers, only one of which is teratogenic (Blaschke et al. 1979). The precise mechanism by which thalidomide causes birth defects has only been identified in recent years. Thalidomide binds to the normal cellular protein CRBN and potentiates its action (Ito et al. 2010). CRBN is a subunit of the CRL $4^{\text {CRBN }}$ E3 ubiquitin ligase that targets a number of proteins for degradation by the ubiquitin pathway. Among its many protein targets is the transcription factor SALL4 (Donovan et al. 2018; Matyskiela et al. 2018). This protein is required in the embryo for both limb and heart development. In humans, deleterious mutants in this gene cause Duane radial ray and Holt-Oram syndromes that both phenocopy the limb and heart defects of thalidomide exposure (Kohlhase et al. 2003). Furthermore, mouse embryos heterozygous for null mutations in this gene have a high frequency of miscarriage and VSDs (Sakaki-Yumoto et al. 2006). Remarkably, this research has also uncovered a mechanism to explain the difference in teratogenicity between humans and rabbits, and rodents. Both rats and mice have amino acid changes in both CRBN and SALL4 that compromise the ability for thalidomide to activate SALL4 degradation (Donovan et al. 2018; Matyskiela et al. 2018).

\section{Retinoic Acid and Vitamin A}

Retinoic acid (RA) is an important signaling molecule synthesized from dietary vitamin A 
that has many roles in embryonic development (Niederreither and Dollé 2008). An excess of RA can have dramatic effects on human embryonic development. This can occur in either the offspring of women undergoing therapeutic treatment with the synthetic retinoid isotretinoin (13-cis-retinoic acid), or in the offspring of women with excess dietary vitamin A supplementation. Isotretinoin was introduced in 1982 as a clinical treatment for severe cystic acne (Peck et al. 1982). Because it was well known from animal experiments that both vitamin A and RA were highly teratogenic (Cohlan 1953; Shenefelt 1972), isotretinoin was labeled a category $\mathrm{X}$ medication (i.e., contraindicated for use during pregnancy). However, it was not long before clinicians were reporting cases of inadvertent use during pregnancy, leading to the frequent occurrence of a range of severe congenital defects, including conotruncal heart defects and AAAs (Lammer et al. 1985). Even today, despite the introduction of a variety of riskreduction programs around the world, there are still significant numbers of pregnancies affected by isotretinoin exposure (Khiali et al. 2018). In embryonic development, RA acts as a morphogen, and it is crucial in such processes as heart development, anteroposterior patterning, limb development, differentiation of mesenchymal tissues, and fine-tuning the left-right signals required for asymmetric organ patterning. In the diet, vitamin A occurs as retinol and is metabolized into retinal and RA using alcohol dehydrogenases (ADHs) and aldehyde dehydrogenases (ALDHs). Some studies suggest that taking vitamin A supplements during the first 12 weeks of gestation (Rothman et al. 1995) or even in the year prior to pregnancy (Botto et al. 1996), results in a more than fourfold increased risk of conotruncal heart defects. However, these results have not been replicated by others (Mills et al. 1997). This may be the result of differences in the source of vitamin A in supplements; isotretinoin was used historically, before being replaced with $\beta$-carotene (provitamin A) more recently. As described above, isotretinoin is highly teratogenic, whereas $\beta$-carotene is not (Shaw et al. 1996; Mastroiacovo et al. 1999). The reason for this difference is unknown. The mechanism by which excess RA can cause CHD has been investigated using animal studies. These show that RA signaling has multiple roles throughout embryonic heart development (Nakajima 2019). These include (1) forming the anteroposterior boundaries of the FHF and SHF cardiogenic mesoderm in the gastrulating embryo prior to heart tube formation; (2) patterning and maintenance of heart progenitors in the anterior SHF, as well as for regulation of their migration and differentiation into the OFT and pharyngeal arches; (3) induction of proliferation of ventricular cardiomyocytes via the epicardium; and (4) formation and patterning of the coronary vasculature, also via the epicardium. Thus, exposure to excess RA can have a variety of effects on embryonic heart development, depending on the timing of the exposure.

\section{Alcohol}

It has been recognized since the 1970s that high dose alcohol consumption (i.e., $\geq 50 \mathrm{~g}$ in a single episode) during pregnancy can lead to fetal alcohol spectrum disorder (FASD) (Jones and Smith 1973). Heart defects are common in FASD, with up to $67 \%$ of cases reported with CHD, mostly VSD, ASD, and conotruncal defects (Burd et al. 2007; Yang et al. 2015). Alcohol is commonly consumed by pregnant women, with up to $30 \%$ of pregnant women and up to $66 \%$ of women who are planning a pregnancy, drinking alcohol (Ethen et al. 2009; Cameron et al. 2013; Green et al. 2016; Reynolds et al. 2019). As a consequence, FASD affects $0.8 \%$ of individuals worldwide (Lange et al. 2017) and up to $5 \%$ of children in the United States (May et al. 2014). However, in the absence of an FASD diagnosis, there may only be a slightly increased risk of $\mathrm{CHD}$ in offspring of mothers drinking periconceptionally (Zhu et al. 2015). Similar to excess RA exposure, animal experiments suggest that the timing and amount of alcohol dictate the nature and severity of the outcomes (Ungerer et al. 2013). The mechanism of alcoholinduced heart defects is not well understood. There are several hypotheses. First, alcohol may act by competitive inhibition of RA synthesis from vitamin A. Alcohol metabolism 
and RA synthesis both require $\mathrm{ADH}$ and ALDHs. These enzymes preferentially detoxify alcohol (Kot-Leibovich and Fainsod 2009), and thus in the presence of alcohol there will be less RA synthesized. In addition, the first breakdown product of alcohol metabolism, acetaldehyde, can inhibit ADH activity, which may further reduce RA synthesis (Shabtai et al. 2018). However, as discussed below, there is little clinical evidence that reduced RA levels affect human embryonic development. Second, ethanol exposure may have a directly deleterious effect on cardiac neural crest cells (Karunamuni et al. 2014). These are cells that arise in the neural tube but, during early development, migrate into the cardiac OFT and pharyngeal arches, and contribute to the valves, septa, and aortic arch arteries. Alcohol is proposed to either causing increased apoptosis and/or impeding migration. Last, it has been suggested that acute alcohol exposure may cause broad epigenetic changes to the embryo by directly affecting DNA methylation, histone modification, and/ or noncoding RNA regulation (Ungerer et al. 2013).

\section{Hypoxia}

In the early 1950s, the first reports of an increased rate of ASD and patent ductus arteriosus cases in infants born at high altitude appeared (Alzamora et al. 1953; Chavez et al. 1953; Espino-Vela 1967). At the same time, the animal experiments in mouse reported adverse effects of hypoxia on embryonic heart development (Ingalls et al. 1952). Maternal exposure to a broad range of reduced oxygen levels for even a short period midgestation causes conotruncal heart defects (Shi et al. 2016; Kenchegowda et al. 2017; Yuan et al. 2017; Moumne et al. 2018). Here, hypoxia reduces the proliferation of SHF cardiac progenitor cells, while FHF differentiated cardiomyocytes are unaffected (Shi et al. 2016; Yuan et al. 2017). By E10.5, this causes a shorter distal OFT and an altered angle between proximal and distal OFT. This leads to malalignment and malrotation of the OFT, and ultimately manifests as conotruncal CHD at E15.5E17.5.
In other studies, midgestation exposure to $8 \%-14 \%$ hypoxia reduces levels of the cardiac transcription factor Nkx2-5, resulting in heart defects (Moumne et al. 2018; Moreau et al. 2019). Exposure of Nkx2-5 null heterozygous embryos to hypoxia in utero exacerbates this effect, resulting in an increased penetrance of heart defects (Moumne et al. 2018) or embryonic death (Moreau et al. 2019). This geneenvironment interaction may explain the $\mathrm{cu}-$ rious clinical observation that complex $\mathrm{CHD}$ rates are significantly reduced in high-altitude populations than in those at sea level (Zheng et al. 2017). This perhaps suggests that at high altitudes, there is an increased mortality rate of fetuses with complex CHD. Another clinically relevant source of embryonic hypoxic exposure is maternal smoking. However, despite the above evidence, this appears to only carry a mildly increased risk of CHD (Correa et al. 2015; Sullivan et al. 2015). The reasons for this disparity are unclear.

\section{Other Therapeutic Drugs}

Many women have serious medical conditions that rely on continuous drug treatment. However, some drugs including anticonvulsants, antiarrhythmics, and antidepressants are also teratogenic. As a result, during pregnancy, difficult decisions may have to be made to balance the risks of damage to the embryo and the risks to the mother. In many cases, understanding how therapeutic drugs cause CHD is complicated by the fact that many drugs have off-target effects. For example, phenytoin is primarily used in the clinic as an anticonvulsant, but it also has antiarrhythmia properties and causes folate deficiency (Lewis et al. 1995). If such a drug is identified as a teratogen, it could cause birth defects via any of these biological activities.

\section{Anticonvulsants}

A potential link between maternal epilepsy and an increased risk of having offspring with birth defects was first proposed in the 1960s. Whether this was a result of the disease itself or the medications taken to control seizures was a topic of 
much debate (Janz and Fuchs 1964). However, by 1970 , it was clear that many of the anticonvulsant drugs in use at the time, including phenytoin, carbamazepine, and valproic acid, were highly teratogenic (Meadow 1970). These drugs result most commonly in VSDs, occurring at a rate three times higher than the general population (Meador et al. 2008). More recently, second- and third-generation anticonvulsants have been developed. Some of these, such as lamotrigine, appear to be less teratogenic (Pariente et al. 2017), others are no better than the older drugs (e.g., topiramate; Vajda et al. 2019), and comprehensive clinical studies are yet to be completed for others (Singh and Verma 2019). The mechanism by which these drugs affect heart development is not well understood as few animal studies have been carried out. The main candidates are perturbation of folic acid metabolism, induction of embryonic hypoxia, or creation of excess oxidative stress (Etemad et al. 2012).

\section{Antiarrhythmics}

Some women have heart conditions causing abnormal heart rhythms that require treatment. In addition, during pregnancy, the mother is subject to characteristic changes in cardiac physiology, including increased heart rate and cardiac output, and changes in hormonal balance and may develop cardiac arrhythmias requiring treatment. However, some antiarrhythmic drugs have been shown in animal models to be highly teratogenic, especially potassium channel blockers (also known as IKr or hERG channel blockers, or class III antiarrhythmics; Danielsson et al. 2001). In addition, a significant number of drugs and natural medicines used for treating other conditions have hERG channel-blocking activity as an unwanted side effect (Rampe and Brown 2013; Kratz et al. 2017). For this reason, compounds with hERG channel-blocking activity are contraindicated for use during pregnancy (Merino and Perez Silva 2011). It is not entirely clear how these drugs affect embryonic development. One attractive theory is that antiarrhythmia drugs reduce embryonic cardiac output, resulting in embryonic hypoxia. In the case of class
III antiarrhythmia drugs, there is some evidence in favor of this hypothesis. hERG-channel inhibitors like dofetilide, when administered to pregnant rats, have been shown to cause embryonic bradycardia and hypoxia (Danielsson et al. 2003; Ritchie et al. 2015).

\section{Antidepressants}

Lithium treatment was first used as a treatment for bipolar disorder in the 1870s, but it took 100 years for such treatment to become mainstream. Today, it is still regarded as the best treatment for long-term relapse prevention (Geddes and Miklowitz 2013). However, it is well established that maternal lithium treatment increases offspring CHD risk (Nora et al. 1974). Modern estimates suggest the increased risk is up to threefold at the highest doses of lithium, and Ebstein's anomaly (tricuspid valve malformation) is particularly prevalent (Patorno et al. 2017). It is thought that lithium causes CHD via aberrant induction of Wnt signaling. Lithium is a well-described inducer of canonical Wnt signaling, via inhibition of the enzyme GSK3 $\beta$ (Stambolic et al. 1996), and this signaling pathway is crucial for multiple stages of embryonic heart development (Ruiz-Villalba et al. 2016). In mouse, dosing with lithium at E8-E9 induces neural tube defects (NTDs), but not heart defects (Jurand 1988; Giles and Bannigan 1997). However, a single intraperitoneal injection of lithium treatment at gastrulation (E6.5) results in $\mathrm{AV}$ and semilunar valve defects by E18.5 (Chen et al. 2008).

Selective serotonin reuptake inhibitors (SSRIs) are the most widely prescribed secondgeneration antidepressant drugs. These drugs have also been implicated in a small increased risk of offspring CHD (Bérard et al. 2017; Gao et al. 2018). However, this is somewhat controversial, as this association may disappear when corrected for confounding factors (Huybrechts et al. 2014). In the brain, SSRIs increase extracellular serotonin levels, by blocking reuptake into neurons. However, serotonin is not just a neurotransmitter. Serotonin signaling is also required for several different aspects of embryonic heart development. These include neural crest 
cell migration, proliferation and survival, and endocardial cushion and trabeculae formation (Yavarone et al. 1993; Choi et al. 1997). Thus, perturbation of serotonin levels by SSRIs may have a direct effect on embryonic heart development. Alternatively, SSRIs might cause heart defects indirectly, as in cultured rat embryos these drugs cause heat block and/or bradycardia, leading to hypoxia (Ababneh et al. 2012).

\section{Nutritional Deficiencies}

In addition to maternal and embryonic exposure to teratogens, there is also evidence that reduced maternal levels of essential nutrients can also increase the risk of CHD in her offspring. However, in many cases, these observations have been made in animal models, and as yet there is little conclusive evidence that these factors are also relevant in humans.

\section{Vitamin A}

As described above, dietary vitamin A is metabolized by the embryo to form RA, a molecule that is intimately involved in many aspects of development. In rodent models, a low vitamin A diet during pregnancy causes highly penetrant heart defects and AAAs (Wilson and Warkany 1950; Kalter and Warkany 1961). This has been confirmed more recently by genetic perturbation of RA synthesis or RA signal transduction in mice, which leads similar embryonic defects. For example, mouse embryos heterozygous for a null Aldh1a2 (formerly Raldh2) allele die by E10.5 with an unlooped, dilated heart (Niederreither et al. 1999), while embryos homozygous for a hypomorphic Aldh1a2 allele have PTA, VSDs, and AAAs (Vermot et al. 2003). Likewise, mouse embryos lacking various combinations of the RAR $\alpha 1, \mathrm{RAR} \beta$, and RXR $\alpha$ RA receptors develop VSDs, conotruncal defects, and AAAs (Lee et al. 1997). However, despite these results, there is no epidemiological evidence of a similar effect in human populations where vitamin A deficiency is prevalent (Azaïs-Braesco and Pascal 2000). Therefore, more research needs to be done to determine the clinical importance of Vitamin A deficiency and CHD risk.

\section{Folic Acid (Vitamin B9)}

Folic acid is a vitamin essential for purine and thymidine synthesis, and as a methyl donor for DNA methylation (Stover 2004). It has been known for over 25 years that low maternal folate levels are associated with a significantly increased risk of NTDs (MRC Vitamin Study Research Group 1991; Czeizel and Dudás 1992). This is the basis for mandatory folic acid fortification of foodstuffs in the United States and Canada, and public health advice in Europe to take folic acid supplements periconceptionally and throughout pregnancy. As a consequence, NTD rates worldwide have dropped by at least 20\% (Honein et al. 2001). It has been suggested that low maternal folate levels may also result in CHD. This has been studied extensively using epidemiology in a variety of human populations. Overall, there is some evidence suggesting that maternal folic acid supplementation during pregnancy might result in lowering $\mathrm{CHD}$ risk by as much as 50\% (Mao et al. 2017; Parnell and Correa 2017; Feng et al. 2018). However, this conclusion is still somewhat controversial, as other studies have not replicated these results (Jenkins et al. 2007; Øyen et al. 2019). In addition, some widely used therapeutic drugs, such as aminopterin and methotrexate, are dihydrofolate reductase inhibitors. These block the conversion of folate to its more active metabolites (Lambie and Johnson 1985). Epidemiological studies show that use of these drugs in the second and third months of pregnancy increases risk of offspring CHD by threefold (Hernández-Díaz et al. 2000; Czeizel et al. 2001). The hypothesis that folate deficiency increases $\mathrm{CHD}$ risk has also been tested using human genetics and animal studies. In humans, epidemiological studies have examined whether deleterious sequence variants in genes encoding folate transporters and metabolic enzymes in either mother or offspring increase risk of CHD. Although some studies suggest a small increase in CHD risk, the largest meta-analyses suggest there is no increase (Mamasoula et al. 2013). Similarly, experiments in mice with reduced folate levels because of genetic and/or dietary deficiency have given inconclusive 
Environmental Risk Factors for CHD

results (Li et al. 2005a; Deng et al. 2008). Here, low maternal and embryonic folate levels lead to higher resorption rates and smaller embryos and placentas. However, it is not clear whether the small increase in VSD rate at E14.5 is a genuine disruption of heart development, or merely the result of developmental delay. The potential role of folate deficiency in CHD is further complicated by its role in DNA methylation and epigenetics. For example, a recent mouse study showed that genetic folate deficiency in a maternal grandparent resulted in two separate effects. First, this had adverse effects on their daughter's uterine environment, leading to growth defects in some grandprogeny, and, second, transgenerational epigenetic effects that resulted in congenital malformations independent of maternal environment (Padmanabhan et al. 2013). Such epigenetic effects may well confound epidemiological studies. In summary, it is unclear whether or not folate deficiency is a clinically important risk factor for offspring $\mathrm{CHD}$, nor is it clear the mechanism by which this might occur.

\section{Hyperhomocysteinemia}

Homocysteine (Hcy) is a sulfur-containing amino acid formed during the metabolism of methionine to cysteine (Kumar et al. 2017). In humans, elevated maternal Hcy levels are associated with an approximately threefold increased risk of having a child with CHD (Kapusta et al. 1999; Verkleij-Hagoort et al. 2006). Hyperhomocysteinemia (HHcy) can be caused by dietary deficiencies in folic acid, vitamin B6, and/or vitamin B12; or by genetic disorders in methionine, homocysteine, or transcobalamin metabolism (Kumar et al. 2017). Since HHcy can often be symptomatic of folate deficiency, it has been proposed that the mechanism by which heart defects are induced in HHcy are the same as for folate deficiency. However, animal studies in both chick and mouse embryos shows that ectopic administration of homocysteine by itself is sufficient to induce septal and valve defects (Rosenquist et al. 1996; Han et al. 2009). Therefore, more work needs to be done to understand the mechanism.

\section{Nicotinamide Adenine Dinucleotide (NAD) and Vitamin B3}

In humans, mutations in either of two genes encoding enzymes in the kynurenine pathway result in a spectrum of congenital abnormalities, including CHD (Shi et al. 2017). This pathway is the de novo NAD synthesis pathway, generating NAD from dietary tryptophan. NAD is an essential cofactor for cell function, and thus it is hypothesized that these congenital abnormalities arise as a direct result of NAD deficiency. This has been successfully modeled in embryos homozygous for null mutations in kynurenine pathway genes, in combination with a low-niacin diet (Shi et al. 2017). Oxidized NAD (NAD ${ }^{+}$) acts as an electron carrier or acceptor for at least 500 different cellular reactions (Kirkland 2012). These include ATP production, biosynthetic pathways and cellular responses to stress. Because of this complexity, it is currently unclear how NAD deficiency causes birth defects. When $\mathrm{NAD}^{+}$accepts electrons, it is reduced to NADH. There is only a small pool of $\mathrm{NAD}^{+}$, so it must be constantly regenerated by transferring the electrons from NADH to another substrate, such as oxygen or pyruvate. NAD is generated either from dietary tryptophan by the de novo pathway, or from dietary niacin or nicotinamide (two forms of vitamin B3) via the salvage pathway. Interestingly, a small epidemiological study showed an increased risk of TGA (but not TOF) in offspring of mothers with the lowest quartile of dietary vitamin B3 intake (Shaw et al. 2010). In embryos with kynurenine pathway mutations, adequate NAD levels during development can be restored with vitamin B3 supplementation, preventing embryonic defects. This suggests that such dietary supplementation with vitamin $\mathrm{B} 3$ may reduce the risk of congenital malformations in humans with NAD deficiency.

\section{Vitamin D}

Recently, a small epidemiological study suggested that even moderate maternal vitamin D deficiency significantly increased offspring CHD risk (Koster et al. 2018). However, this study 
J.I. Kalisch-Smith et al.

was flawed as vitamin D levels were measured 15 months after birth. The idea that vitamin D signaling might be important for embryonic heart development is supported by a study in a zebrafish model, where knockdown of both vitamin $\mathrm{D}$ receptors simultaneously during embryonic development resulted in abnormal AV boundary specification and cardiac laterality defects (Kwon 2016). However, it is currently unclear whether vitamin $\mathrm{D}$ deficiency is a significant contributor to $\mathrm{CHD}$ worldwide.

\section{INTRINSIC FACTORS}

In addition to extrinsic factors, maternal diseases and infections that change the uterine environment can also impact embryonic development. These factors can result in the accumulation of a teratogenic substance, such as glucose or phenylalanine. Alternatively, they can alter the uterine environment more directly, as in maternal hyperthermia.

\section{Diabetes}

Diabetes mellitus is a metabolic disorder characterized by hyperglycemia as a result of poor insulin secretion, detection, or action (National Diabetes Action Group 1979). It is estimated that 425 million people have diabetes, and it is predicted that this will rise to 629 million by 2045 (International Diabetes Federation 2017). There are three main types of diabetes. Type I typically arises via an autoimmune-mediated destruction of pancreatic $\beta$ cells, and culminates in a rapid decline in insulin production and persistent hyperglycemia. Type II is usually associated with obesity and aging, and results from a lack of insulin secretion and diminished insulin sensitivity because of obesity-related $\beta$-cell loss. Gestational diabetes is a transient disease similar to type II that develops during pregnancy, but resolves following parturition. Offspring of mothers with preexisting diabetes (types I and II) have an approximately threefold increased risk of any type of CHD (Hoang et al. 2017), and gestational diabetes carries an approximately 1.5-fold increased CHD risk (Hoang et al. 2017). This is also the case when the data is adjusted for potential confounders such as maternal body mass index, alcohol use, and age. In addition, these children have elevated risks for other developmental abnormalities such spina bifida, anencephaly, craniofacial anomalies, and macrosomia. When broken down into specific subtypes, it is clear that some of these carry a particularly increased risk, for example, the risk of PTA is increased 14-fold (Hoang et al. 2017). The mechanism by which maternal diabetes increases CHD risk is far from clear (Basu and Garg 2018). This is because it is a complex metabolic disease. In addition to hyperglycemia, patients may also present with hyperlipidemia (Abbate and Brunzell 1990), protein misfolding and glycation (Scheuner and Kaufman 2008; Singh et al. 2014), and impaired glucose tolerance and impaired insulin sensitivity. However, prevalence of offspring CHD correlates with increasing or poorly controlled maternal blood glucose levels (BGLs), measured by glycated haemoglobin, HbAlc (Priest et al. 2015), strongly suggesting that hyperglycemia is the primary teratogen. Despite this assumption, there is no consensus on how hyperglycemia causes CHD. Extensive investigation in a variety of animal models has led to many disparate hypotheses, including hypoxia and/or increased oxidative stress (Li et al. 2005b), activation of the polyol or hexosamine pathways (Sussman and Matschinsky 1988; Horal et al. 2004), increased apoptosis (Gäreskog et al. 2007), or endoplasmic reticulum stress (Wang et al. 2013). However, because diabetes is such a multifaceted disease, it is also possible that a combination of these events results in CHD.

\section{Obesity}

Maternal obesity during pregnancy (antenatal body mass index $>30$ ) is associated with many pregnancy-related adverse outcomes including reduced fertility, miscarriage, and stillbirth (Guelinckx et al. 2008), as well as an increased risk of CHD and NTDs (Stothard et al. 2009). This is a health concern of increasing importance, as currently $>15 \%$ of women of childbearing age are obese, a further $40 \%$ are overweight, and these numbers are rapidly growing (World 
Health Organization 2018). Like diabetes mellitus, obesity is a complex metabolic disease. In particular, it is often accompanied by type II diabetes, or impaired glucose tolerance at the very least, making the two diseases difficult to separate. Therefore, the prevailing hypothesis is that obesity and diabetes-induced congenital malformations may share a common etiology. Human and animal studies rarely account for impaired glucose tolerance during obese pregnancies and, therefore, fail to provide an unbiased account of the effect of obesity alone. One exception concluded that increased maternal weight was associated with increased risk for CHD after adjusting for glucose tolerance (Brite et al. 2014). However, exactly how increased maternal weight in isolation might affect embryonic heart development is as yet unknown.

\section{Phenylketonuria}

Phenylketonuria (PKU) is an inborn error of metabolism, where dietary phenylalanine (Phe) cannot be metabolized (Blau et al. 2010). Patients have very high blood Phe levels, which result in cognitive decline, growth failure, poor pigmentation, developmental delay, and seizures. These phenotypes are the result of an accumulation of toxic by-products of improper Phe metabolism. Clinically, PKU can be managed using a low Phe diet from birth. This keeps the majority of the complications under control. Originally, such treatment was only continued until puberty. However, because of a growing awareness of continued complications of PKU in adults, it is now recommended that such treatment is lifelong (National Institutes of Health Consensus Development Panel 2001). One major complication for women is a highly increased risk of having offspring with intrauterine growth restriction and/or birth defects, including microcephaly and CHD. This is likely to be a direct consequence of increased Phe levels, as women with poor dietary control have significantly higher rates of offspring with defects (Platt et al. 2000). Overall, there is a greater than sixfold increased risk of CHD in offspring of mothers with PKU (Platt et al. 2000; Levy et al. 2001). This has been mimicked in studies in mouse and chick (Seagraves and McBride 2012; Watson and Seagraves 2019). Transcriptomic analysis of the chick model suggests that phenylalanine teratogenicity may act through dysregulation of RA signaling (Watson and Seagraves 2019). This is supported by the observation that the characteristic facial phenotype of PKU-affected patients is often very similar to those of FASD (Levy and Ghavami 1996), which has also been associated with perturbed RA signaling (see above). Exactly how elevated Phe levels might affect RA signaling or metabolism awaits further investigation.

\section{Viral Infection and Hyperthermia}

Maternal infection with rubella during the first 10 weeks of pregnancy causes birth defects in up to $90 \%$ of cases, and may result in stillbirth or miscarriage (Gregg 1941). Cardiac defects are present in about half of these cases, with branch pulmonary artery stenosis, patent ductus arteriosus, and VSD, the most prevalent forms of CHD observed (Vince 1970; Oster et al. 2010). This risk factor has largely been controlled by mass vaccination programs, but in recent years falling vaccination rates have led to increased numbers of rubella outbreaks worldwide. First trimester infection with other viruses, and fever in general, also carry an increased risk of offspring CHD (Dreier et al. 2014; Luteijn et al. 2014; Shi et al. 2014). Although exactly how maternal viral infection causes birth defects is not clear, there is some evidence that the increased body temperature (hyperthermia) is the teratogen, rather than the virus itself. This is supported by animal studies, the earliest of which was the serendipitous observation from a guinea pig colony housed in an uninsulated shed during a Sydney heat wave that resulted in spontaneous abortions and limb defects (Edwards 1967). Subsequent studies in many species have confirmed that maternal hyperthermia can cause a range of embryonic defects, including heart defects (Edwards 2006). Various mechanisms have been proposed, but there is little evidence for most of these. Two of these seem most likely. First, hyperthermia results in activation of the heat shock response, which is a 
J.I. Kalisch-Smith et al.

subset of the unfolded protein response (UPR) (Barna et al. 2018). Therefore, it is possible that hyperthermia acts by the same mechanism as hypoxia (see above) (Shi et al. 2016). Alternatively, a recent study very elegantly shows that two temperature-activated ion channels expressed in neural crest cells might be responsible (Hutson et al. 2017). They show that activation of these channels by temperature or chemical agonist treatment replicated hyperthermia-induced defects in chick embryos. Furthermore, they showed that treatment with antagonists of these ion channels protected against the effects of hyperthermia. Hyperthermia can also potentially occur via physical activity or exposure to high environmental temperatures. Such nonviral hyperthermia may also result in CHD. For example, one epidemiological study found that maternal exposure to 3-11 cumulative days or more of extreme heat ( $\geq 95$ percentile daily maximum temperature) between weeks 3-8 of pregnancy carries an increased CHD risk of $\sim 50 \%$ (Lin et al. 2018).

\section{CONCLUDING REMARKS}

A significant proportion of $\mathrm{CHD}$ cases are likely to be caused by environmental risk factors; however, it has been relatively difficult to clearly identify specific factors or their mechanism of action. Although the embryonic consequences of maternal rubella infection and thalidomide use were identified readily through observation and anecdotal report, large-scale epidemiological studies have been required to identify other potential risk factors (Erickson 1991). Such studies are complicated by the fact that the period of human embryonic heart development that is vulnerable to teratogenic perturbation is gestational weeks $3-8$. However, even with the advent of routine ultrasonography, detection of CHD may only occur perinatally, when accurate details of the mother's health status or teratogen exposure details 6 months previously may be difficult to ascertain and collect. In addition, differences in $\mathrm{CHD}$ recording and classification between different countries may further complicate analysis (EuroCAT: network.eu/accesspre valencedata/interpretationguide/interpretatio nofprevelancerates). Animal studies have also been useful in identifying and confirming environmental risk factors. However, the experience with thalidomide, which does not cause birth defects in rodents (Schumacher et al. 1968), underlines the difficulties of relying on animal experimentation as a sole measure of cardiac teratogenicity. Therefore, there may be other significant environmental risk factors for $\mathrm{CHD}$ that are yet to be identified. These may include factors identified from demographic studies that suggest differing $\mathrm{CHD}$ rates in populations stratified by age, ethnicity, socioeconomic grouping, and geographical location (van der Linde et al. 2011).

Advances in understanding how embryonic heart development occurs now provides tools for understanding how extrinsic and intrinsic factors acting on the mother can perturb the formation of the heart. This could potentially make it possible for the first time to significantly reduce the prevalence of $\mathrm{CHD}$ worldwide. Studies identifying genetic causes of CHD have often resulted in useful diagnostic and predictive capacity in a case-by-case manner for genetic counseling in individual families. However, genetic studies cannot suggest strategies for reducing the general population-wide risks of $\mathrm{CHD}$. By contrast, studies of the environmental causes of CHD potentially could be directly translated to provide clinical impact. Understanding the molecular mechanisms of induction of CHD by a range of environmental and genetic factors, and identifying the stages in heart formation that are most vulnerable to these factors will aid the design of epidemiological studies to assess the extent of these risks in human CHD. It will also guide the formulation of health policy recommendations to aid women planning pregnancy to minimize their exposure to such environmental risks.

\section{ACKNOWLEDGMENTS}

D.B.S. and J.I.K.-S. are supported by funding from the British Heart Foundation (FS/17/55/ 33100 and $\mathrm{RE} / 13 / 1 / 30181)$. N.V. is supported by a Novo Nordisk postdoctoral fellowship run in partnership with the University of Oxford. 


\section{REFERENCES}

Ababneh D, Ritchie H, Webster WS. 2012. Antidepressants cause bradycardia and heart block in GD 13 rat embryos in vitro. Birth Defects Res B Dev Reprod Toxicol 95: 184193. doi:10.1002/bdrb.21003

Abbate SL, Brunzell JD. 1990. Pathophysiology of hyperlipidemia in diabetes mellitus. J Cardiovasc Pharmacol 16 (Suppl 9): S1-S7. doi:10.1097/00005344-19900016900002

Abbott ME. 1908. Congenital cardiac disease. In Modern medicine: Its theory and practice (ed. Osler W), pp. 323425. Lea and Febiger, Philadelphia.

Alzamora V, Rotta A, Battilana G, Abugattas R, Rubio C, Bouroncle J, Zapata C, Santa-Maria E, Binder T, Subiria $\mathrm{R}$, et al. 1953. On the possible influence of great altitudes on the determination of certain cardiovascular anomalies. Pediatrics 12: 259-262.

Azaïs-Braesco V, Pascal G. 2000. Vitamin A in pregnancy: requirements and safety limits. Am J Clin Nutr 71: 1325S1333S. doi:10.1093/ajen/71.5.1325s

Barna J, Csermely P, Vellai T. 2018. Roles of heat shock factor 1 beyond the heat shock response. Cell Mol Life Sci 75: 2897-2916. doi:10.1007/s00018-018-2836-6

Basu M, Garg V. 2018. Maternal hyperglycemia and fetal cardiac development: clinical impact and underlying mechanisms. Birth Defects Res 110: 1504-1516. doi:10 $.1002 / \mathrm{bdr} 2.1435$

Bérard A, Zhao JP, Sheehy O. 2017. Antidepressant use during pregnancy and the risk of major congenital malformations in a cohort of depressed pregnant women: an updated analysis of the Quebec Pregnancy Cohort. BMJ Open 7: e013372. doi:10.1136/bmjopen-2016-013372

Blaschke G, Kraft HP, Fickentscher K, Kohler F. 1979. Chromatographic separation of racemic thalidomide and teratogenic activity of its enantiomers (author transl). Arzneimittelforschung 29: 1640-1642.

Blau N, van Spronsen FJ, Levy HL. 2010. Phenylketonuria. Lancet 376: 1417-1427. doi:10.1016/S0140-6736(10) 60961-0

Botto LD, Khoury MJ, Mulinare J, Erickson JD. 1996. Periconceptional multivitamin use and the occurrence of conotruncal heart defects: results from a populationbased, case-control study. Pediatrics 98: 911-917.

Brite J, Laughon SK, Troendle J, Mills J. 2014. Maternal overweight and obesity and risk of congenital heart defects in offspring. Int J Obes (Lond) 38: 878-882. doi:10 $.1038 /$ ijo.2013.244

Bruneau BG. 2008. The developmental genetics of congenital heart disease. Nature 451: 943-948. doi:10.1038/na ture 06801

Burd L, Deal E, Rios R, Adickes E, Wynne J, Klug MG. 2007. Congenital heart defects and fetal alcohol spectrum disorders. Congenit Heart Dis 2: 250-255. doi:10.1111/j $.1747-0803.2007 .00105 . x$

Cameron CM, Davey TM, Kendall E, Wilson A, McClure RJ. 2013. Changes in alcohol consumption in pregnant Australian women between 2007 and 2011. Med J Aust 199: 355-357. doi:10.5694/mja12.11723

Campbell M. 1949. Genetic and environmental factors in congenital heart disease. Q J Med 18: 379-391.
Chavez I, Espino Vela J, Limon R, Dorbecker N. 1953. Patent ductus arteriosus; studies on 200 cases. Arch Inst Cardiol Mex 23: 687-755.

Chen J, Han M, Manisastry SM, Trotta P, Serrano MC, Huhta JC, Linask KK. 2008. Molecular effects of lithium exposure during mouse and chick gastrulation and subsequent valve dysmorphogenesis. Birth Defects Res A Clin Mol Teratol 82: 508-518. doi:10.1002/bdra.20448

Choi DS, Ward SJ, Messaddeq N, Launay JM, Maroteaux L. 1997. 5-HT2B receptor-mediated serotonin morphogenetic functions in mouse cranial neural crest and myocardiac cells. Development 124: 1745-1755.

Cohlan SQ. 1953. Excessive intake of vitamin A as a cause of congenital anomalies in the rat. Science 117: 535-536. doi:10.1126/science.117.3046.535

Correa A, Levis DM, Tinker SC, Cragan JD. 2015. Maternal cigarette smoking and congenital heart defects. J Pediatr 166: 801-804. doi:10.1016/j.jpeds.2015.01.013

Czeizel AE, Dudás I. 1992. Prevention of the first occurrence of neural-tube defects by periconceptional vitamin supplementation. NEngl J Med 327: 1832-1835. doi:10.1056/ NEJM199212243272602

Czeizel AE, Rockenbauer M, Sørensen HT, Olsen J. 2001. The teratogenic risk of trimethoprim-sulfonamides: a population-based case-control study. Reprod Toxicol 15: 637-646. doi:10.1016/S0890-6238(01)00178-2

Danielsson BR, Skold AC, Azarbayjani F. 2001. Class III antiarrhythmics and phenytoin: teratogenicity due to embryonic cardiac dysrhythmia and reoxygenation damage. Curr Pharm Des 7: 787-802. doi:10.2174/1381612 013397744

Danielsson BR, Sköld AC, Johansson A, Dillner B, Blomgren B. 2003. Teratogenicity by the hERG potassium channel blocking drug almokalant: use of hypoxia marker gives evidence for a hypoxia-related mechanism mediated via embryonic arrhythmia. Toxicol Appl Pharmacol 193: 168-176. doi:10.1016/j.taap.2003.07.002

Deng L, Elmore CL, Lawrance AK, Matthews RG, Rozen R. 2008. Methionine synthase reductase deficiency results in adverse reproductive outcomes and congenital heart defects in mice. Mol Genet Metab 94: 336-342. doi:10.1016/ j.ymgme.2008.03.004

Dietz HC, Cutting GR, Pyeritz RE, Maslen CL, Sakai LY, Corson GM, Puffenberger EG, Hamosh A, Nanthakumar EJ, Curristin SM, et al. 1991. Marfan syndrome caused by a recurrent de novo missense mutation in the fibrillin gene. Nature 352: 337-339. doi:10.1038/352337a0

Donovan KA, An J, Nowak RP, Yuan JC, Fink EC, Berry BC, Ebert BL, Fischer ES. 2018. Thalidomide promotes degradation of SALL4, a transcription factor implicated in Duane radial ray syndrome. eLife 7: e38430. doi:10 $.7554 /$ eLife. 38430

Dreier JW, Andersen AM, Berg-Beckhoff G. 2014. Systematic review and meta-analyses: fever in pregnancy and health impacts in the offspring. Pediatrics 133: e674e688. doi:10.1542/peds.2013-3205

Edwards MJ. 1967. Congenital defects in guinea pigs. Following induced hyperthermia during gestation. Arch Pathol 84: 42-48.

Edwards MJ. 2006. Review: hyperthermia and fever during pregnancy. Birth Defects Res A Clin Mol Teratol 76: 507516. doi:10.1002/bdra.20277 
J.I. Kalisch-Smith et al.

Erickson JD. 1991. Risk factors for birth defects: data from the Atlanta birth defects case-control study. Teratology 43: 41-51. doi:10.1002/tera.1420430106

Espino-Vela J. 1967. Congenital cardiac malformations in high altitude populations. World Health Organization, Washington, DC.

Etemad L, Moshiri M, Moallem SA. 2012. Epilepsy drugs and effects on fetal development: potential mechanisms. $J$ Res Med Sci 17: 876-881.

Ethen MK, Ramadhani TA, Scheuerle AE, Canfield MA, Wyszynski DF, Druschel CM, Romitti PA, National Birth Defects Prevention Study. 2009. Alcohol consumption by women before and during pregnancy. Matern Child Health J 13: 274-285. doi:10.1007/s10995-008-0328-2

Feng Y, Cai J, Tong X, Chen R, Zhu Y, Xu B, Mo X. 2018. Non-inheritable risk factors during pregnancy for congenital heart defects in offspring: a matched case-control study. Int J Cardiol 264: 45-52. doi:10.1016/j.ijcard.2018 .04 .003

Ford CE, Jones KW, Polani PE, De Almeida JC, Briggs JH. 1959. A sex-chromosome anomaly in a case of gonadal dysgenesis (Turner's syndrome). Lancet 273: 711-713. doi:10.1016/S0140-6736(59)91893-8

Gao SY, Wu QJ, Sun C, Zhang TN, Shen ZQ, Liu CX, Gong TT, Xu X, Ji C, Huang DH, et al. 2018. Selective serotonin reuptake inhibitor use during early pregnancy and congenital malformations: a systematic review and metaanalysis of cohort studies of more than 9 million births. BMC Med 16: 205. doi:10.1186/s12916-018-1193-5

Gäreskog M, Cederberg J, Eriksson UJ, Wentzel P. 2007. Maternal diabetes in vivo and high glucose concentration in vitro increases apoptosis in rat embryos. Reprod Toxicol 23: 63-74. doi:10.1016/j.reprotox.2006.08.009

Geddes JR, Miklowitz DJ. 2013. Treatment of bipolar disorder. Lancet 381: 1672-1682. doi:10.1016/S0140-6736(13) 60857-0

Giles JJ, Bannigan JG. 1997. The effects of lithium on neurulation stage mouse embryos. Arch Toxicol 71: 519-528. doi:10.1007/s002040050422

Green PP, McKnight-Eily LR, Tan CH, Mejia R, Denny CH. 2016. Vital signs: Alcohol-exposed pregnancies-United States, 2011-2013. MMWR Morb Mortal Wkly Rep 65: 91-97. doi:10.15585/mmwr.mm6504a6

Gregg NM. 1941. Congenital cataract following German measles in the mother. Trans Ophthalmol Soc Aust 3: $35-46$.

Guelinckx I, Devlieger R, Beckers K, Vansant G. 2008. Maternal obesity: Pregnancy complications, gestational weight gain and nutrition. Obes Rev 9: 140-150. doi:10 $.1111 /$ j.1467-789X.2007.00464.x

Han M, Serrano MC, Lastra-Vicente R, Brinez P, Acharya G, Huhta JC, Chen R, Linask KK. 2009. Folate rescues lithium-, homocysteine- and Wnt3A-induced vertebrate cardiac anomalies. Dis Model Mech 2: 467-478. doi:10.1242/ dmm.001438

Hernández-Díaz S, Werler MM, Walker AM, Mitchell AA. 2000. Folic acid antagonists during pregnancy and the risk of birth defects. N Engl J Med 343: 1608-1614. doi:10.1056/NEJM200011303432204

Hoang TT, Marengo LK, Mitchell LE, Canfield MA, Agopian AJ. 2017. Original findings and updated meta-analysis for the association between maternal diabetes and risk for congenital heart disease phenotypes. Am J Epidemiol 186: 118-128. doi:10.1093/aje/kwx033

Honein MA, Paulozzi LJ, Mathews TJ, Erickson JD, Wong LY. 2001. Impact of folic acid fortification of the US food supply on the occurrence of neural tube defects. JAMA 285: 2981-2986. doi:10.1001/jama.285.23.2981

Horal M, Zhang Z, Stanton R, Virkamäki A, Loeken MR. 2004. Activation of the hexosamine pathway causes oxidative stress and abnormal embryo gene expression: involvement in diabetic teratogenesis. Birth Defects Res A Clin Mol Teratol 70: 519-527. doi:10.1002/bdra.20056

Hutson MR, Keyte AL, Hernandez-Morales M, Gibbs E, Kupchinsky ZA, Argyridis I, Erwin KN, Pegram K, Kneifel M, Rosenberg PB, et al. 2017. Temperature-activated ion channels in neural crest cells confer maternal feverassociated birth defects. Sci Signal 10: eaa14055. doi:10 $.1126 /$ scisignal.aal 4055

Huybrechts KF, Palmsten K, Avorn J, Cohen LS, Holmes LB, Franklin JM, Mogun H, Levin R, Kowal M, Setoguchi S, et al. 2014. Antidepressant use in pregnancy and the risk of cardiac defects. N Engl J Med 370: 2397-2407. doi:10 .1056/NEJMoa1312828

Ingalls TH, Curley FJ, Prindle RA. 1952. Experimental production of congenital anomalies; timing and degree of anoxia as factors causing fetal deaths and congenital anomalies in the mouse. $N$ Engl J Med 247: 758-768. doi:10.1056/NEJM195211132472004

International Diabetes Federation. 2017. Global factsheet. www.idf.org/aboutdiabetes/what-is-diabetes/facts-figures .html

Ito T, Ando H, Suzuki T, Ogura T, Hotta K, Imamura Y, Yamaguchi Y, Handa H. 2010. Identification of a primary target of thalidomide teratogenicity. Science 327: 13451350. doi:10.1126/science.1177319

Janz D, Fuchs U. 1964. Are anti-epileptic drugs harmful during pregnancy? Dtsch Med Wochenschr 89: 241-243. doi:10.1055/s-0028-1111011

Jenkins KJ, Correa A, Feinstein JA, Botto L, Britt AE, Daniels SR, Elixson M, Warnes CA, Webb CL; American Heart Association Council on Cardiovascular Disease in the Young. 2007. Noninherited risk factors and congenital cardiovascular defects: current knowledge: a scientific statement from the American Heart Association council on cardiovascular disease in the young: endorsed by the American Academy of Pediatrics. Circulation 115: 29953014. doi:10.1161/CIRCULATIONAHA.106.183216

Jones KL, Smith DW. 1973. Recognition of the fetal alcohol syndrome in early infancy. Lancet 302: 999-1001. doi:10 .1016/S0140-6736(73)91092-1

Jurand A. 1988. Teratogenic activity of lithium carbonate: an experimental update. Teratology 38: 101-111. doi:10 $.1002 /$ tera. 1420380202

Kalter H, Warkany J. 1961. Experimental production of congenital malformations in strains of inbred mice by maternal treatment with hypervitaminosis A. Am J Pathol 38: $1-21$.

Kapusta L, Haagmans ML, Steegers EA, Cuypers MH, Blom HJ, Eskes TK. 1999. Congenital heart defects and maternal derangement of homocysteine metabolism. J Pediatr 135: 773-774. doi:10.1016/S0022-3476(99)70102-2 
Karunamuni GH, Ma P, Gu S, Rollins AM, Jenkins MW, Watanabe M. 2014. Connecting teratogen-induced congenital heart defects to neural crest cells and their effect on cardiac function. Birth Defects Res C Embryo Today 102: 227-250. doi:10.1002/bdrc.21082

Kenchegowda D, Natale B, Lemus MA, Natale DR, Fisher SA. 2017. Inactivation of maternal Hif- $1 \alpha$ at mid-pregnancy causes placental defects and deficits in oxygen delivery to the fetal organs under hypoxic stress. Dev Biol 422: 171-185. doi:10.1016/j.ydbio.2016.12.013

Khiali S, Gharekhani A, Entezari-Maleki T. 2018. Isotretinoin: a review on the utilization pattern in pregnancy. $A d v$ Pharm Bull 8: 377-382. doi:10.15171/apb.2018.044

Kirkland JB. 2012. Niacin requirements for genomic stability. Mutat Res 733: 14-20. doi:10.1016/j.mrfmmm.2011 .11 .008

Kohlhase J, Schubert L, Liebers M, Rauch A, Becker K, Mohammed SN, Newbury-Ecob R, Reardon W. 2003. Mutations at the SALL4 locus on chromosome 20 result in a range of clinically overlapping phenotypes, including Okihiro syndrome, Holt-Oram syndrome, acro-renalocular syndrome, and patients previously reported to represent thalidomide embryopathy. J Med Genet 40: 473-478. doi:10.1136/jmg.40.7.473

Koster MPH, van Duijn L, Krul-Poel YHM, Laven JS, Helbing WA, Simsek S, Steegers-Theunissen RPM. 2018. A compromised maternal vitamin D status is associated with congenital heart defects in offspring. Early Hum Dev 117: 50-56. doi:10.1016/j.earlhumdev.2017.12.011

Kot-Leibovich H, Fainsod A. 2009. Ethanol induces embryonic malformations by competing for retinaldehyde dehydrogenase activity during vertebrate gastrulation. Dis Model Mech 2: 295-305. doi:10.1242/dmm.001420

Kratz JM, Grienke U, Scheel O, Mann SA, Rollinger JM. 2017. Natural products modulating the hERG channel: heartaches and hope. Nat Prod Rep 34: 957-980. doi:10 .1039/C7NP00014F

Kumar A, Palfrey HA, Pathak R, Kadowitz PJ, Gettys TW Murthy SN. 2017. The metabolism and significance of homocysteine in nutrition and health. Nutr Metab (Lond) 14: 78. doi:10.1186/s12986-017-0233-z

Kwon HJ. 2016. Vitamin D receptor signaling is required for heart development in zebrafish embryo. Biochem Biophys Res Commun 470: 575-578. doi:10.1016/j.bbrc.2016.01 .103

Lambie DG, Johnson RH. 1985. Drugs and folate metabolism. Drugs 30: 145-155. doi:10.2165/00003495-19 8530020-00003

Lammer EJ, Chen DT, Hoar RM, Agnish ND, Benke PJ, Braun JT, Curry CJ, Fernhoff PM, Grix AW, Lott IT, et al. 1985. Retinoic acid embryopathy. $N$ Engl J Med 313: 837-841. doi:10.1056/NEJM198510033131401

Lange S, Probst C, Gmel G, Rehm J, Burd L, Popova S. 2017. Global prevalence of fetal alcohol spectrum disorder among children and youth: a systematic review and meta-analysis. JAMA Pediatr 171: 948-956. doi:10 $.1001 /$ jamapediatrics.2017.1919

Lee RY, Luo J, Evans RM, Giguere V, Sucov HM. 1997. Compartment-selective sensitivity of cardiovascular morphogenesis to combinations of retinoic acid receptor gene mutations. Circ Res 80: 757-764. doi:10.1161/01.RES.80.6 .757
Lejeune J, Gauthier M, Turpin R. 1959. Human chromosomes in tissue cultures. C R Hebd Seances Acad Sci 248: 602-603.

Lenz W. 1961. Thalidomide and congenital anomalies. Lancet 1: 45 .

Levy HL, Ghavami M. 1996. Maternal phenylketonuria: a metabolic teratogen. Teratology 53: 176-184. doi:10.1002/ (SICI) 1096-9926(199603)53:3<176::AID-TERA5>3.0. $\mathrm{CO} ; 2-2$

Levy HL, Guldberg P, Güttler F, Hanley WB, Matalon R, Rouse BM, Trefz F, Azen C, Allred EN, de la Cruz F, et al. 2001. Congenital heart disease in maternal phenylketonuria: report from the maternal PKU collaborative study. Pediatr Res 49: 636-642. doi:10.1203/00006450200105000-00005

Lewis DP, Van Dyke DC, Willhite LA, Stumbo PJ, Berg MJ. 1995. Phenytoin-folic acid interaction. Ann Pharmacother 29: 726-735. doi:10.1177/106002809502907-816

Li D, Pickell L, Liu Y, Wu Q, Cohn JS, Rozen R. 2005a. Maternal methylenetetrahydrofolate reductase deficiency and low dietary folate lead to adverse reproductive outcomes and congenital heart defects in mice. Am J Clin Nutr 82: 188-195. doi:10.1093/ajcn/82.1.188

Li R, Chase M, Jung SK, Smith PJ, Loeken MR. 2005b. Hypoxic stress in diabetic pregnancy contributes to impaired embryo gene expression and defective development by inducing oxidative stress. Am J Physiol Endocrinol Metab 289: E591-E599. doi:10.1152/ajpendo.00441.2004

Lin S, Lin Z, Ou Y, Soim A, Shrestha S, Lu Y, Sheridan S, Luben TJ, Fitzgerald E, Bell E, et al. 2018. Maternal ambient heat exposure during early pregnancy in summer and spring and congenital heart defects-a large US population-based, case-control study. Environ Int 118: 211221. doi:10.1016/j.envint.2018.04.043

Luteijn JM, Brown MJ, Dolk H. 2014. Influenza and congenital anomalies: a systematic review and meta-analysis Hum Reprod 29: 809-823. doi:10.1093/humrep/det455

Mamasoula C, Prentice RR, Pierscionek T, Pangilinan F, Mills JL, Druschel C, Pass K, Russell MW, Hall D, Töpf A, et al. 2013. Association between C677T polymorphism of methylene tetrahydrofolate reductase and congenital heart disease: meta-analysis of 7697 cases and 13,125 controls. Circ Cardiovasc Genet 6: 347-353. doi:10 $.1161 /$ CIRCGENETICS.113.000191

Mao B, Qiu J, Zhao N, Shao Y, Dai W, He X, Cui H, Lin X, Lv L, Tang Z, et al. 2017. Maternal folic acid supplementation and dietary folate intake and congenital heart defects. PLoS ONE 12: e0187996. doi:10.1371/journal.pone .0187996

Mastroiacovo P, Mazzone T, Addis A, Elephant E, Carlier P, Vial T, Garbis H, Robert E, Bonati M, Ornoy A, et al. 1999. High vitamin A intake in early pregnancy and major malformations: A multicenter prospective controlled study. Teratology 59: 7-11. doi:10.1002/(SICI)10969926(199901)59:1<7::AID-TERA4>3.0.CO;2-6

Matyskiela ME, Couto S, Zheng X, Lu G, Hui J, Stamp K, Drew C, Ren Y, Wang M, Carpenter A, et al. 2018. SALL4 mediates teratogenicity as a thalidomide-dependent cereblon substrate. Nat Chem Biol 14: 981-987. doi:10.1038/ s41589-018-0129-x

May PA, Baete A, Russo J, Elliott AJ, Blankenship J, Kalberg WO, Buckley D, Brooks M, Hasken J, Abdul-Rahman O, 
J.I. Kalisch-Smith et al.

et al. 2014. Prevalence and characteristics of fetal alcohol spectrum disorders. Pediatrics 134: 855-866. doi:10 $.1542 /$ peds.2013-3319

McBride WG. 1961. Thalidomide and congenital abnormalities. Lancet 278: 1358. doi:10.1016/S0140-6736(61) 90927-8

Meador K, Reynolds MW, Crean S, Fahrbach K, Probst C. 2008. Pregnancy outcomes in women with epilepsy: a systematic review and meta-analysis of published pregnancy registries and cohorts. Epilepsy Res 81: 1-13. doi:10.1016/j.eplepsyres.2008.04.022

Meadow SR. 1970. Congenital abnormalities and anticonvulsant drugs. Proc $R$ Soc Med 63: 48-49.

Merino JL, Perez Silva A. 2011. Tachyarrhythmias and pregnancy. E J Cardiol Prac 9: 31.

Mills JL, Simpson JL, Cunningham GC, Conley MR, Rhoads GG. 1997. Vitamin A and birth defects. Am J Obstet Gynecol 177: 31-36. doi:10.1016/S0002-9378(97)70434-4

Moreau JLM, Kesteven S, Martin E, Lau KS, Yam MX, O’Reilly VC, Del Monte-Nieto G, Baldini A, Feneley MP, Moon AM, et al. 2019. Gene-environment interaction impacts on heart development and embryo survival Development 146: dev172957. doi:10.1242/dev.172957

Moumne O, Chowdhurry R, Doll C, Pereira N, Hashimi M, Grindrod T, Dollar JJ, Riva A, Kasahara H. 2018. Mechanism sharing between genetic and gestational hypoxiainduced cardiac anomalies. Front Cardiovasc Med 5: 100. doi:10.3389/fcrm.2018.00100

MRC Vitamin Study Research Group. 1991. Prevention of neural tube defects: results of the medical research council vitamin study. Lancet 338: 131-137. doi:10.1016/01406736(91)90133-A

Nakajima Y. 2019. Retinoic acid signaling in heart development. Genesis 57: e23300. doi:10.1002/dvg.23300

National Diabetes Action Group. 1979. Classification and diagnosis of diabetes mellitus and other categories of glucose intolerance. Diabetes 28: 1039-1057. doi:10.2337/ diab.28.12.1039

National Institutes of Health Consensus Development Panel. 2001. National institutes of health consensus development conference statement: phenylketonuria: screening and management, October 16-18, 2000. Pediatrics 108: 972-982. doi:10.1542/peds.108.4.972

Niederreither K, Dollé P. 2008. Retinoic acid in development: towards an integrated view. Nat Rev Genet 9: 541-553. doi:10.1038/nrg2340

Niederreither K, Subbarayan V, Dollé P, Chambon P. 1999. Embryonic retinoic acid synthesis is essential for early mouse post-implantation development. Nat Genet 21: 444-448. doi:10.1038/7788

Nora JJ. 1968. Multifactorial inheritance hypothesis for the etiology of congenital heart diseases. The genetic-environmental interaction. Circulation 38: 604-617. doi:10 $.1161 / 01 . C I R .38 .3 .604$

Nora JJ, Nora AH, Toews WH. 1974. Letter: Lithium, Ebstein's anomaly, and other congenital heart defects. Lancet 304: 594-595. doi:10.1016/S0140-6736(74)91918-7

Oster ME, Riehle-Colarusso T, Correa A. 2010. An update on cardiovascular malformations in congenital rubella syndrome. Birth Defects Res A Clin Mol Teratol 88: 1-8.
Øyen N, Olsen SF, Basit S, Leirgul E, Strøm M, Carstensen L, Granström C, Tell GS, Magnus P, Vollset SE, et al. 2019. Association between maternal folic acid supplementation and congenital heart defects in offspring in birth cohorts from Denmark and Norway. J Am Heart Assoc 8: e011615. doi:10.1161/JAHA.118.011615

Padmanabhan N, Jia D, Geary-Joo C, Wu X, FergusonSmith AC, Fung E, Bieda MC, Snyder FF, Gravel RA, Cross JC, et al. 2013. Mutation in folate metabolism causes epigenetic instability and transgenerational effects on development. Cell 155: 81-93. doi:10.1016/j.cell.2013.09 .002

Pariente G, Leibson T, Shulman T, Adams-Webber T, Barzilay E, Nulman I. 2017. Pregnancy outcomes following in utero exposure to lamotrigine: a systematic review and meta-analysis. CNS Drugs 31: 439-450. doi:10.1007/ s40263-017-0433-0

Parnell AS, Correa A. 2017. Analyses of trends in prevalence of congenital heart defects and folic acid supplementation. J Thorac Dis 9: 495-500. doi:10.21037/jtd.2017.03 .16

Patorno E, Huybrechts KF, Bateman BT, Cohen JM, Desai RJ, Mogun H, Cohen LS, Hernandez-Diaz S. 2017. Lithium use in pregnancy and the risk of cardiac malformations. N Engl J Med 376: 2245-2254. doi:10.1056/NEJ Moa1612222

Peacock T. 1858. On malformations of the human heart. John Churchill, London.

Peck GL, Olsen TG, Butkus D, Pandya M, Arnaud-Battandier J, Gross EG, Windhorst DB, Cheripko J. 1982. Isotretinoin versus placebo in the treatment of cystic acne. A randomized double-blind study. J Am Acad Dermatol 6: 735-745. doi:10.1016/S0190-9622(82)70063-5

Pfeiffer RA, Kosenow W. 1961. Thalidomide and congenital anomalies. Lancet 1: 45-46.

Platt LD, Koch R, Hanley WB, Levy HL, Matalon R, Rouse B, Trefz F, de la Cruz F, Guttler F, Azen C, et al. 2000. The international study of pregnancy outcome in women with maternal phenylketonuria: report of a 12-year study. $A m \mathrm{~J}$ Obstet Gynecol 182: 326-333. doi:10.1016/S0002-9378 (00)70219-5

Priest JR, Yang W, Reaven G, Knowles JW, Shaw GM. 2015. Maternal midpregnancy glucose levels and risk of congenital heart disease in offspring. JAMA Pediatr 169: 1112-1116. doi:10.1001/jamapediatrics.2015.2831

Rampe D, Brown AM. 2013. A history of the role of the hERG channel in cardiac risk assessment. J Pharmacol Toxicol Methods 68: 13-22. doi:10.1016/j.vascn.2013.03 .005

Reynolds CME, Egan B, O'Malley EG, McMahon L, Sheehan SR, Turner MJ. 2019. Fetal growth and maternal alcohol consumption during early pregnancy. Eur J Obstet Gynecol Reprod Biol 236: 148-153. doi:10.1016/j.ejogrb.2019 .02 .005

Rickert-Sperling S, Kelly RG, Driscoll DJ. eds. 2016. Congenital heart disease: the broken heart. Springer, Vienna.

Ritchie H, Oakes D, Hung TT, Hegedus E, Sood S, Webster W. 2015. The effect of dofetilide on the heart rate of GD11 and GD13 rat embryos, in vivo, using ultrasound. Birth Defects Res B Dev Reprod Toxicol 104: 196-203. doi:10 $.1002 /$ bdrb. 21162 
Rosenquist TH, Ratashak SA, Selhub J. 1996. Homocysteine induces congenital defects of the heart and neural tube: effect of folic acid. Proc Natl Acad Sci 93: 15227-15232. doi:10.1073/pnas.93.26.15227

Rothman KJ, Moore LL, Singer MR, Nguyen US, Mannino S, Milunsky A. 1995. Teratogenicity of high vitamin A intake. $N$ Engl J Med 333: 1369-1373. doi:10.1056/ NEJM199511233332101

Ruffing L. 1977. Evaluation of thalidomide children. Birth Defects Orig Artic Ser 13: 287-300.

Ruiz-Villalba A, Hoppler S, van den Hoff MJ. 2016. Wnt signaling in the heart fields: variations on a common theme. Dev Dyn 245: 294-306. doi:10.1002/dvdy.24372

Sakaki-Yumoto M, Kobayashi C, Sato A, Fujimura S, Matsumoto Y, Takasato M, Kodama T, Aburatani H, Asashima M, Yoshida N, et al. 2006. The murine homolog of SALL4, a causative gene in Okihiro syndrome, is essential for embryonic stem cell proliferation, and cooperates with Sall1 in anorectal, heart, brain and kidney development. Development 133: 3005-3013. doi:10.1242/dev .02457

Scheuner D, Kaufman RJ. 2008. The unfolded protein response: a pathway that links insulin demand with $\beta$-cell failure and diabetes. Endocr Rev 29: 317-333. doi:10 $.1210 /$ er.2007-0039

Schumacher H, Blake DA, Gurian JM, Gillette JR. 1968. A comparison of the teratogenic activity of thalidomide in rabbits and rats. J Pharmacol Exp Ther 160: 189-200.

Seagraves NJ, McBride KL. 2012. Cardiac teratogenicity in mouse maternal phenylketonuria: defining phenotype parameters and genetic background influences. Mol Genet Metab 107: 650-658. doi:10.1016/j.ymgme.2012.08 .001

Shabtai Y, Bendelac L, Jubran H, Hirschberg J, Fainsod A. 2018. Acetaldehyde inhibits retinoic acid biosynthesis to mediate alcohol teratogenicity. Sci Rep 8: 347 . doi:10 .1038/s41598-017-18719-7

Shaw GM, Wasserman CR, Block G, Lammer EJ. 1996. High maternal vitamin A intake and risk of anomalies of structures with a cranial neural crest cell contribution. Lancet 347: 899-900. doi:10.1016/S0140-6736(96)91377-X

Shaw GM, Carmichael SL, Yang W, Lammer EJ. 2010. Periconceptional nutrient intakes and risks of conotruncal heart defects. Birth Defects Res A Clin Mol Teratol 88: 144-151.

Shenefelt RE. 1972. Morphogenesis of malformations in hamsters caused by retinoic acid: relation to dose and stage at treatment. Teratology 5: 103-118. doi:10.1002/ tera. 1420050115

Shi QY, Zhang JB, Mi YQ, Song Y, Ma J, Zhang YL. 2014. Congenital heart defects and maternal fever: systematic review and meta-analysis. J Perinatol 34: 677-682. doi:10 $.1038 /$ jp.2014.76

Shi H, O’Reilly VC, Moreau JL, Bewes TR, Yam MX, Chapman BE, Grieve SM, Stocker R, Graham RM, Chapman G, et al. 2016. Gestational stress induces the unfolded protein response, resulting in heart defects. Development 143: 2561-2572. doi:10.1242/dev.136820

Shi H, Enriquez A, Rapadas M, Martin E, Wang R, Moreau J, Lim CK, Szot JO, Ip E, Hughes JN, et al. 2017. NAD deficiency, congenital malformations, and niacin supple- mentation. N Engl J Med 377: 544-552. doi:10.1056/NEJ Moa1616361

Singh KP, Verma N. 2019. Teratogenic potential of thirdgeneration antiepileptic drugs: current status and research needs. Pharmacol Rep 71: 491-502. doi:10.1016/j.pharep .2019.01.011

Singh VP, Bali A, Singh N, Jaggi AS. 2014. Advanced glycation end products and diabetic complications. Korean J Physiol Pharmacol 18: 1-14. doi:10.4196/kjpp.2014 .18 .1 .1

Stambolic V, Ruel L, Woodgett JR. 1996. Lithium inhibits glycogen synthase kinase- 3 activity and mimics wingless signaling in intact cells. Curr Biol 6: 1664-1668. doi:10 .1016/S0960-9822(02)70790-2

Stothard KJ, Tennant PW, Bell R, Rankin J. 2009. Maternal overweight and obesity and the risk of congenital anomalies: a systematic review and meta-analysis. JAMA 301: 636-650. doi:10.1001/jama.2009.113

Stover PJ. 2004. Physiology of folate and vitamin $\mathrm{B}_{12}$ in health and disease. Nutr Rev 62: S3-S12. discussion S13. doi:10.1111/j.1753-4887.2004.tb00070.x

Sullivan PM, Dervan LA, Reiger S, Buddhe S, Schwartz SM. 2015. Risk of congenital heart defects in the offspring of smoking mothers: a population-based study. J Pediatr 166: 978-984.e2. doi:10.1016/j.jpeds.2014.11.042

Sussman I, Matschinsky FM. 1988. Diabetes affects sorbitol and myo-inositol levels of neuroectodermal tissue during embryogenesis in rat. Diabetes 37: 974-981. doi:10.2337/ diab.37.7.974

Szot JO, Cuny H, Blue GM, Humphreys DT, Ip E, Harrison K, Sholler GF, Giannoulatou E, Leo P, Duncan EL, et al. 2018. A screening approach to identify clinically actionable variants causing congenital heart disease in exome data. Circ Genom Precis Med 11: e001978.

Taussig HB. 1947. Congenital malformations of the heart. Commonwealth Fund, New York.

Ungerer M, Knezovich J, Ramsay M. 2013. In utero alcohol exposure, epigenetic changes, and their consequences. Alcohol Res 35: 37-46.

Vajda FJE, Graham JE, Hitchcock AA, Lander CM, O’Brien TJ, Eadie MJ. 2019. Antiepileptic drugs and foetal malformation: analysis of 20 years of data in a pregnancy register. Seizure 65: 6-11. doi:10.1016/j.seizure.2018.12 .006

van der Linde D, Konings EE, Slager MA, Witsenburg M, Helbing WA, Takkenberg JJ, Roos-Hesselink JW. 2011. Birth prevalence of congenital heart disease worldwide: a systematic review and meta-analysis. J Am Coll Cardiol 58: 2241-2247. doi:10.1016/j.jacc.2011.08.025

Verkleij-Hagoort AC, Verlinde M, Ursem NT, Lindemans J, Helbing WA, Ottenkamp J, Siebel FM, Gittenberger-de Groot AC, de Jonge R, Bartelings MM, et al. 2006. Maternal hyperhomocysteinaemia is a risk factor for congenital heart disease. BJOG 113: 1412-1418. doi:10.1111/j .1471-0528.2006.01109.x

Vermot J, Niederreither K, Garnier JM, Chambon P, Dolle P. 2003. Decreased embryonic retinoic acid synthesis results in a DiGeorge syndrome phenotype in newborn mice. Proc Natl Acad Sci 100: 1763-1768. doi:10.1073/pnas .0437920100 
J.I. Kalisch-Smith et al.

Vince DJ. 1970. The hospital incidence and clinical significance of congenital heart malformations resulting from rubella embryopathy. Can Med Assoc J 102: 374376.

Wang F, Reece EA, Yang P. 2013. Superoxide dismutase 1 overexpression in mice abolishes maternal diabetes-induced endoplasmic reticulum stress in diabetic embryopathy. Am J Obstet Gynecol 209: 345.e1-345.e7. doi:10 .1016/j.ajog.2013.03.022

Watson JN, Seagraves NJ. 2019. RNA-Seq analysis in an avian model of maternal phenylketonuria. Mol Genet Metab 126: 23-29. doi:10.1016/j.ymgme.2018.09.003

Wilson JG, Warkany J. 1950. Cardiac and aortic arch anomalies in the offspring of vitamin A deficient rats correlated with similar human anomalies. Pediatrics 5: 708-725.

World Health Organization. 2018. Obesity and overweight fact sheet. www.who.int/news-room/fact-sheets/detail/ obesity-and-overweight

Yang J, Qiu H, Qu P, Zhang R, Zeng L, Yan H. 2015. Prenatal alcohol exposure and congenital heart defects: a meta- analysis. PLoS ONE 10: e0130681. doi:10.1371/journal .pone. 0130681

Yavarone MS, Shuey DL, Tamir H, Sadler TW, Lauder JM. 1993. Serotonin and cardiac morphogenesis in the mouse embryo. Teratology 47: 573-584. doi:10.1002/tera.14 20470609

Yuan X, Qi H, Li X, Wu F, Fang J, Bober E, Dobreva G, Zhou Y, Braun T. 2017. Disruption of spatiotemporal hypoxic signaling causes congenital heart disease in mice. J Clin Invest 127: 2235-2248. doi:10.1172/JCI88725

Zheng JY, Qiu YG, Li DT, He JC, Chen Y, Cao Y, Liu YM, Li XF, Chi HT, Li TC. 2017. Prevalence and composition of CHD at different altitudes in Tibet: a cross-sectional study. Cardiol Young 27: 1497-1503. doi:10.1017/ S1047951117000567

Zhu Y, Romitti PA, Caspers Conway KM, Shen DH, Sun L, Browne ML, Botto LD, Lin AE, Druschel CM, National Birth Defects Prevention Study. 2015. Maternal periconceptional alcohol consumption and congenital heart defects. Birth Defects Res A Clin Mol Teratol 103: 617-629. doi:10.1002/bdra.23352 


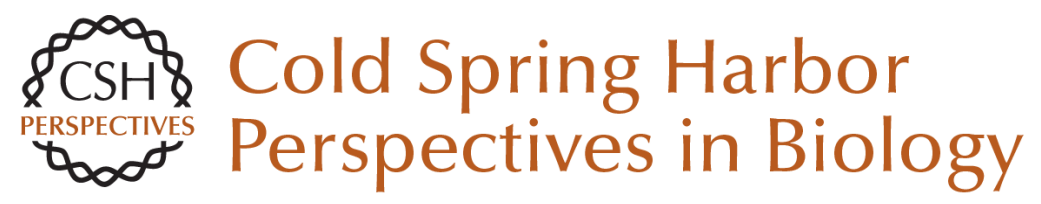

\section{Environmental Risk Factors for Congenital Heart Disease}

Jacinta Isabelle Kalisch-Smith, Nikita Ved and Duncan Burnaby Sparrow

Cold Spring Harb Perspect Biol 2020; doi: 10.1101/cshperspect.a037234 originally published online September 23, 2019

\section{Subject Collection Heart Development and Disease}

Epicardium in Heart Development

Yingxi Cao, Sierra Duca and Jingli Cao

Cardiac Neural Crest

Hiroyuki Yamagishi

The Endocardium and Heart Valves Bailey Dye and Joy Lincoln

Long Noncoding RNAs in Cardiac Development Michael Alexanian and Samir Ounzain

Genetic Basis of Human Congenital Heart Disease Shannon N. Nees and Wendy K. Chung

Cardiopharyngeal Progenitor Specification:

Multiple Roads to the Heart and Head Muscles Benjamin Swedlund and Fabienne Lescroart

Genetic and Epigenetic Control of Heart Development

Brynn N. Akerberg and William T. Pu

Formation and Growth of Cardiac Lymphatics during Embryonic Development, Heart Regeneration, and Disease

Dana Gancz, Gal Perlmoter and Karina Yaniv
In Vivo and In Vitro Genetic Models of Congenital Heart Disease Uddalak Majumdar, Jun Yasuhara and Vidu Garg

Development of the Cardiac Conduction System Samadrita Bhattacharyya and Nikhil V. Munshi

3D Anatomy of the Developing Heart:

Understanding Ventricular Septation

Timothy J. Mohun and Robert H. Anderson

Cardiac Morphogenesis: Specification of the

Four-Chambered Heart

Vincent Christoffels and Bjarke Jensen

The Chicken as a Model Organism to Study Heart

Development

Johannes G. Wittig and Andrea Münsterberg

The First Heartbeat--Origin of Cardiac Contractile

Activity

Richard C.V. Tyser and Shankar Srinivas

Xenopus: Experimental Access to Cardiovascular

Development, Regeneration Discovery, and

Cardiovascular Heart-Defect Modeling Stefan Hoppler and Frank L. Conlon

Reptiles as a Model System to Study Heart

Development

Bjarke Jensen and Vincent M. Christoffels

For additional articles in this collection, see http://cshperspectives.cshlp.org/cgi/collection/

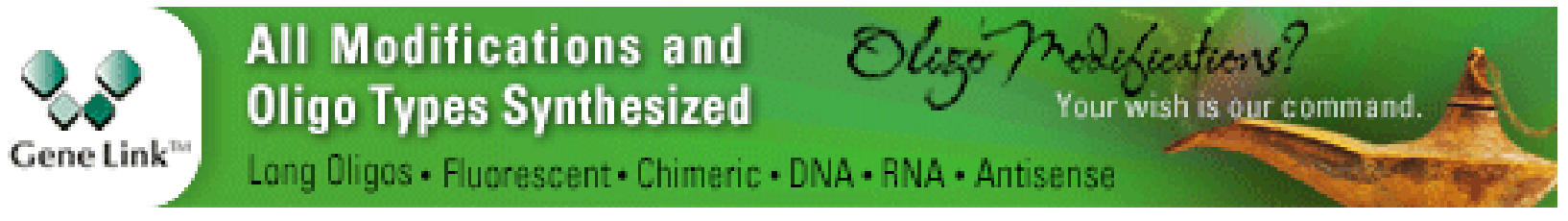

Copyright @ 2020 Cold Spring Harbor Laboratory Press; all rights reserved 